\title{
10454
}

\section{DIRECT INTEGRATION TRANSMITTANCE MODEL}

(NASA-TH-X-70454) DIRECT INTEGBATIO
(NASA) 39 P BC

TRANSMITTANCE HODEL (NASA) $39 \mathrm{P}$ 


\section{DIRECT INTEGRATION TRANSMITTANCE MODEL}

V. G. Kunde

W. C. Maguire

Laboratory for Planetary Atmospheres

July 1973

GODDARD SPACE FLIGHT CENTER

Greenbelt, Maryland 


\title{
DIRECT INTEGRATION TRANSMITTANCE MODEL
}

\author{
V. G. Kunde \\ W. C. Maguire
}

Laboratory for Planetary Atmospheres

\section{ABSTRACT}

A transmittance model has been developed for the $200-2000 \mathrm{~cm}^{-1}$ region for interpretation of high spectral resolution measurements of laboratory absorption and of planetary thermal emission. The high spectral resolution requires transmittances to be computed monochromatically by summing the contribution of individual molecular absorption lines. A magnetic tape atlas of $\mathrm{H}_{2} \mathrm{O}, \mathrm{O}_{3}$, and $\mathrm{CO}_{2}$ molecular line parameters serves as input to the transmittance model with simple empirical representations used for continuum regions wherever suitable laboratory data exist. The theoretical formulation of the transmittance model and the computational procedures used for the evaluation of the transmittances are discussed, and application of the model to several homogenous path laboratory absorption examples is demonstrated. 
CONTENTS

Page

ABSTRACT $\ldots \ldots \ldots \ldots \ldots \ldots \ldots \ldots \ldots \ldots \ldots \ldots \ldots \ldots \ldots \ldots \ldots$ iii

INTRODUCTION $\ldots \ldots \ldots \ldots \ldots \ldots \ldots \ldots \ldots \ldots \ldots \ldots \ldots$

INFRARED RADIATIVE TRANSFER THEORY .......... 2

Homogenous Path Theory $\ldots \ldots \ldots \ldots \ldots \ldots \ldots \ldots$

Slant Path Theory $\ldots \ldots \ldots \ldots \ldots \ldots \ldots \ldots \ldots \ldots$

MONOCHROMATIC MOLECULAR ABSORPTION COEFFICIENT

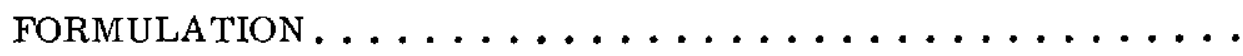

SOURCES FOR MOLECULAR TRANSMITTANCE

PARAMETERS . ..................

CONCLUDING REMARKS $\ldots \ldots \ldots \ldots \ldots \ldots \ldots \ldots$

ACKNOWLEDGMENTS . . . . . . . . . . . . . . . 24

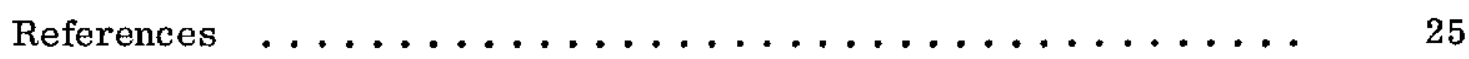




\section{INTRODUCTION}

Improved spectral resolution in infrared measurements has required a corresponding improvement in the theoretical and analytical techniques for interpreting the measurements, particularly in the area of molecular absorption. Data of intermediate to high spectral resolution in the infrared are now available for the Earth from the Nimbus 4 interferometer spectrometer (HANEL et al. (1)); for the Moon, Venus, and Mars from ground-based observations (CONNES et al. (2), HANEL et al. (3), and RANK $\left.{ }^{(4)}\right)$; and for Mars from the interferometer spectrometer on the Mariner 9 orbiter (HANEL et al. (5)). High spectral ressolution infrared measurements are also available for stellar sources (CONNES et al. ${ }^{(6)}$, GEBALLE et aI. $\left.{ }^{(7)}\right)$. Representation of the molecular absorption by band models and empirical fits to laboratory absorption data is no longer adequate for interpretation of the high spectral resolution measurements (DRAYSON ${ }^{(8)}$ ). The need for high spectral resolution and for versatility in changing parameters such as spectral resolution, instrument function, and molecular line parameters requires new techniques for handling molecular absorption.

One of the techniques that has been successfully developed is the direct integration method, which involves the computation of the monochromatic absorption spectrum by numerically summing the contributions of the individual. molecular absorption lines. This technique has been applied to interpretation 
of planetary and stellar infrared spectra (DRAYSON (8), KYLE (9), KUNDE (10), AUMAN (11), QUERCI et al. (12)). Direct integration programs for homogenous path applications have been developed by CALFEE (13) and by ARNOLD et al. (14). This paper describes a direct integration transmittance model developed by the authors for interpretation of laboratory absorption and planetary thermal emission spectra in the $200-2000 \mathrm{~cm}^{-1}$ region. The application of the model to laboratory absorption data is also presented. The model has been used previously to interpret planetary thermal emission spectra of the Earth and Mars obtained with the interferometer spectrometers on Nimbus 4 and Mariner 9 (Hanel, et al. ${ }^{(5)}$, Kunde, et al. $\left.{ }^{(15)}\right)$. In subsequent papers the transmittance model will also be applied to the interpretation of ground-based planetary observations of Venus and Mars.

The formulation of the infrared radiative transfer equation for homogenous and slant path problems is given in Section 2; the formulation of monochromatic molecular absorption coefficients is outlined in Section 3; and the sources of the various molecular line parameters are discussed in Section 4.

\section{INF RARED RADIATIVE TRANSFER THEORY}

This section reviews the general theory and mathematical formulation governing the radiative transfer of infrared radiation through a single layer of absorbing gas in which the physical state of the gas does not vary (homogenous path problem), and a series of layers at varying temperatures and pressures (slant path problem). The homogenous path problem is generally applicable to 
laboratory absorption measurements, while the slant path problem relates to the transfer of radiation through a planetary atmosphere. A specific application of the formalism developed in this section and the adopted numerical techniques will be discussed in Section 3.

For computational efficiency, the general procedure adopted for both problems is to compute the average transmittance of radiance for $\Delta \nu$ intervals which are much smaller than the instrumental resolution. The observed transmittances or radiances are then obtained by convolving the computed spectrum with the instrument function. In this paper, the value $\Delta \nu=0.1 \mathrm{~cm}^{-1}$ has been adopted.

Homogenous Path Theory

With the assumption of local thermodynamic equilibrium, the spectral radiance $\left(\mathrm{N}_{\nu}\right)$ from a slab of a mixture of absorbing gases at uniform temperature (T) and pressure (P) may be written in its most general from as

$$
\mathrm{N}_{\nu}=\mathrm{N}_{\nu}^{0} \exp \left[-\sum_{\mathrm{i}} \mathrm{k}_{\nu}^{\mathrm{i}}(\mathrm{P}, \mathrm{T}) \mathrm{u}_{\mathrm{i}}\right]+\mathrm{B}_{\nu}(\mathrm{T})\left[1-\exp \left(-\sum_{\mathrm{i}} \mathrm{k}_{\nu}^{\mathrm{i}}(\mathrm{P}, \mathrm{T}) \mathrm{u}_{\mathrm{i}}\right)\right]
$$

with the optical path length $\mathrm{u}=\rho \mathrm{L}$. The geometrical path length is $\mathrm{L}$, the total molecular absorption coefficient for the $\mathrm{i}$-th gas is $\mathrm{k}_{\nu}^{\mathrm{i}}(\mathrm{P}, \mathrm{T})$, the gas density is $\rho_{\mathrm{i}}$, the Planck function is $\mathrm{B}_{\nu}(\mathrm{T})$, and $\mathrm{N}_{\nu}^{\circ}$ is the external incident intensity on the slab of gases at $L=o$. The first term on the right represents the transmitted radiance; and the second term, the thermal emission of the gas. If the thermal 
emission is negligible (ku very small), Equation (1) reduces to

$$
\tau_{\nu}=\frac{\mathrm{N}_{\nu}}{\mathrm{N}_{\nu}^{0}}=\exp \left[-\sum_{\mathrm{i}} \mathrm{k}_{\nu}^{\mathrm{i}}(\mathrm{P}, \mathrm{T}) \mathrm{u}_{\mathrm{i}}\right]
$$

where $\tau_{\nu}$ is the monochromatic transmission through the absorbing gas. The transmittance averaged over a small spectral interval, $\Delta \nu$, is

$$
\bar{\tau}_{\Delta \nu}=\frac{\int \tau_{\nu} \mathrm{d} \nu}{\Delta \nu}
$$

which is numerically evaluated using Legendre-Gauss quadrature (STROUD and SECREST $(16)$ ). Each $\Delta v$ spectral interval is divided into a variable number of subintervals $(k=1,2 \ldots K)$ with four-point Lengendre-Gauss quadrature ( $\ell=$ $1,2 \ldots 4)$ used for each subinterval. Equation (3) now may be written as

$$
\bar{\tau}_{\Delta \nu}=\frac{\sum_{\mathrm{k}=1}^{\mathrm{K}}\left(\frac{\nu_{\mathrm{B}_{\mathrm{k}}}-\nu_{\mathrm{A}_{\mathrm{k}}}}{2}\right) \sum_{\ell=1}^{4} \mathrm{w}_{\ell} \tau_{\nu_{\mathrm{k} \ell}}}{\Delta \nu}
$$

where

$$
\nu_{\mathrm{k} \ell}=\frac{\nu_{\mathrm{B}_{\mathrm{k}}}-\nu_{\mathrm{A}_{\mathrm{k}}}}{2} \mathrm{x}_{\ell}+\frac{\nu_{\mathrm{B}_{\mathrm{k}}}+\nu_{\mathrm{A}_{\mathrm{k}}}}{2}
$$

with $\nu_{B}$ and $\nu_{A}$ being the upper and lower wave number boundaries of the subinterval, respective; and $w_{\ell}$ and $x_{\ell}$ the Legendre-Gauss weights and abscissa, respectively. 
Associated with all spectrometers is an instrument function, $f\left(\left|v-v_{n}\right|, a\right)$, which degrades the true monochromatic spectrum at wave number $\nu_{\mathrm{n}}$ to

$$
\vec{\tau}_{\nu_{\mathrm{n}}}=\int_{-\infty}^{+\infty} \mathrm{f}\left(\left|\nu-\nu_{\mathrm{n}}\right|, \mathrm{a}\right) \tau_{\nu} \mathrm{d} \nu
$$

where a represents the full width of the instrument function at half maximum. The instrument function has been normalized

$$
\int_{-\infty}^{+\infty} \mathrm{f}\left(\left|\nu-\nu_{n}\right|, a\right) \mathrm{d} \nu=1
$$

Assuming $\Delta \nu$ is small enough that $f\left(\left|v-\nu_{\mathrm{n}}\right|\right.$, a) is essentially constant over $\Delta \nu$, Equation (6) can be approximated by

$$
\bar{\tau}_{\nu_{\mathbf{n}}}=\sum \overline{\mathrm{f}}\left(\left|\nu-\nu_{\mathbf{n}}\right|, \mathrm{a}\right) \bar{\tau}_{\Delta \nu} \Delta \nu
$$

with $f\left(\left|\nu-\nu_{n}\right|\right.$, a) representing the average value of the instrument function over the $\Delta v$ interval. The principal advantage of evaluating the instrument-averaged transmittance from the approximation in Equation (8), using the transmittances initially averaged over $\Delta \nu$ intervals rather than directly from Equation (6), is a large saving in computer storage. In the approximate scheme the monochromatic transmittances need not be save after $\tau_{\Delta \nu}$ is computed, thus saving a factor of $\sim 100$ in core storage. The approximation scheme is adequate as long as a $\gg \Delta \nu$. 
The convolution of Equation (8) can also be represented in terms of the Fourier transforms of the functions involved:

$$
\bar{\tau}^{*}(\mathrm{t})=\bar{f}^{*}(\mathrm{t}) \cdot \overline{\tau_{\Delta \nu}^{*}}(\mathrm{t})
$$

with $t$ indicating the time domain and the asterisk denoting the Fourier transform. In the time domain the convolution reduces to a multiplication. For a large spectral range or for small values of $\Delta \nu$ it becomes more efficient to determine $\tau_{\nu_{\mathrm{n}}}$ through the fast Fourier transfrom technique rather than through the direct convolution process. (17)

Slant Path Theory

The emergent thermal emission spectrum at the top of the atmosphere has its origin in the radiant ene rgy processes occurring in the planetary atmosphere and at the planetary surface. The emergent monochromatic radiance, neglecting scattering processes, is given by the radiative transfer equation as

$$
\mathrm{N}_{\nu}\left(\mathrm{S}_{\mathrm{T}}\right)=\epsilon_{\nu s} \mathrm{~B}_{\nu}\left(\mathrm{T}_{\mathrm{s}}\right) \tau_{\nu}\left(0, \mathrm{~S}_{\mathrm{T}}\right)+\mathrm{r}_{\nu_{\mathrm{s}}} \mathrm{F}_{\nu_{\mathrm{S}}}^{-} \tau_{\nu}\left(0, \mathrm{~S}_{\mathrm{T}}\right)+\int_{\tau_{\nu}(0,0)}^{\tau_{\nu}\left(0, \mathrm{~S}_{\mathrm{T}}\right)} \mathrm{B}_{\nu}\left[\mathrm{T}\left(\mathrm{s}^{\prime}\right)\right] \mathrm{d} \tau_{\nu}\left(\mathrm{s}^{\prime}, \mathrm{S}_{\mathrm{T}}\right)
$$

The integration is through the planetary atmosphere along any geometric slant path (s) from the planetary lower boundary surface $(s=0)$ to the top of the atmosphere $\left(\mathrm{s}=\mathrm{S}_{\mathrm{T}}\right)$. A schematic of the radiation components and definition of some of the slant path parameters is shown in Figure 1. The emergent radiance consists of the surface emission, the downward atmospheric radiation flux reflected from the planetary surface, and the atmospheric emission. The emissive 
characteristics of the surface are described by $\epsilon_{\nu_{s}^{\prime}}$, atmospheric transmittance between levels $\mathrm{s}$ and $\mathrm{S}_{\mathrm{T}}$ by $\tau_{\nu}\left(\mathrm{s}, \mathrm{S}_{\mathrm{T}}\right)$, reflectivity for a perfectly diffuse reflector by $\mathrm{r}_{\nu_{\mathrm{s}}}$, and the downward atmospheric flux by $\pi \mathrm{F}_{\nu_{\mathrm{s}}}$. The subscript $\mathrm{s}$ denotes planetary surface parameters. The reflected component can generally be neglected as most surfaces are blackbody or near-black-body in character $\left(\mathbf{r}_{\nu_{\mathrm{s}}} \sim 0\right)$. An exception to this occurs over surface areas where the strong reststrahlen bands may yield a significant reflected component:

The monochromatic transmittance through an inhomogenous medium of a mixture of gases is

$$
\tau_{\nu}\left(\mathrm{s}, \mathrm{S}_{\mathrm{T}}\right)=\exp \left[-\int_{\mathrm{s}}^{\mathrm{s}} \sum_{\mathrm{i}} \mathrm{k}_{\nu}^{\mathrm{i}}(\mathrm{P}, \mathrm{T}) \rho_{\mathrm{i}} \mathrm{ds} \mathrm{s}^{\prime}\right]
$$

With the optical path length for the i-th gas

$$
u_{i}=\int \rho_{i} \mathrm{ds}
$$

we can approximate the integration along the atmospheric slant path by a series of isothermal, constant pressure layers $(j=1,2, \ldots, \mathrm{J})$ as .

$$
\tau_{\nu}\left(s, s_{T}\right)=\exp \left[-\sum_{j} \sum_{i} k_{\nu}^{i j}\left(\bar{P}_{j}, \bar{T}_{j}\right) \Delta u_{j}\right]
$$

where the $\mathrm{j}$-summation includes all atmospheric layers between levels $\mathrm{s}$ and $\mathbf{S}_{\mathrm{T}}$, and $\overline{\mathrm{P}}$ and $\overline{\mathrm{T}}$ are the average pressure and temperature for a layer. We can define a slant path average transmittance, similar to the homogenous path 
average transmittance, in terms of four-point Legendre-Gauss quadrature

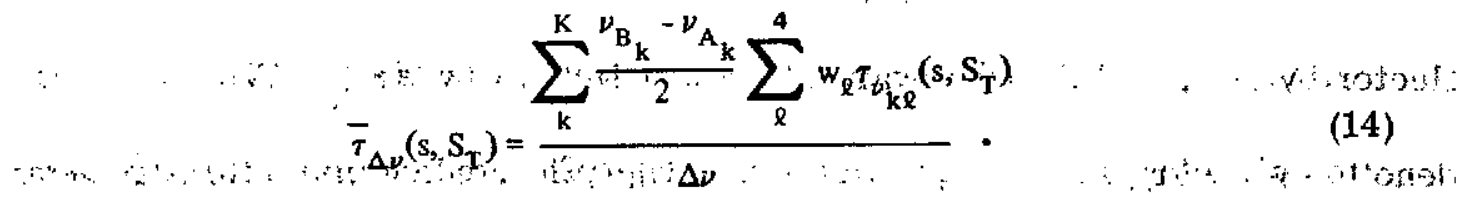

The radiative transfer formulation given above describes only the general approach used to determine the emergent spectrum for any atmospheric slant path, s, through a model atmospherei. A more detailed description of the techniques used to relate the slant path, $s$, to the local vertical path, $h$, for a spherical atmosphere and for the determination of the optical path lengths of the various absorbing gases along s has been given previously (KUNDE (18)).

The emergent spectral radiance in a finite spectral interval, $\Delta \nu$, is

$$
\mathrm{N}_{\Delta \nu}\left(\mathrm{S}_{\mathrm{T}}\right)=\int_{\Delta \nu} \mathrm{N}_{\nu}\left(\mathrm{S}_{\mathrm{T}}\right) \mathrm{d} \nu \quad \cdots
$$

With Equation (10) and assuming that $\Delta \nu$ is small enough to allow the spectral quantities to be evaluated at the midpoint of $\Delta \nu$ (denoted by $\nu^{\prime}$ ), Equation (15) may be expressed in terms of the average transmittance as

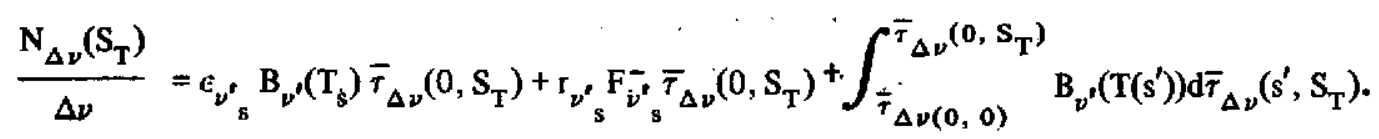

We can numerically approximate Equation (16) by

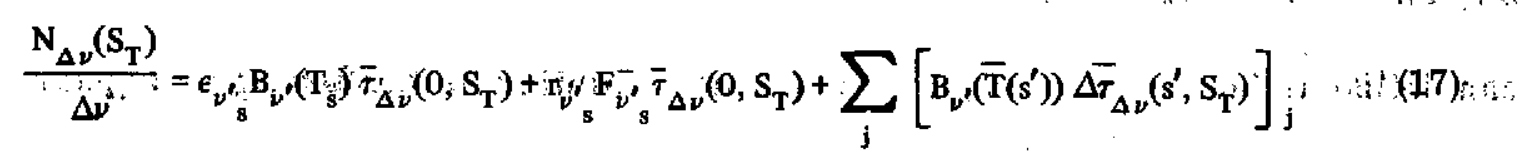


where the atmosphere has been divided into a series of isothermal layers with the integral term of Equation (16) being replaced by a sum over the contributions of all atmospheric layers. The difference in transmission across the layer is $\Delta \bar{\tau}_{\Delta \nu_{\mathrm{j}}}$ with the layer increment taken as $\Delta \mathrm{s}^{\prime}=0.1 \mathrm{~km}$. To evaluate Equation (17) the average transmittance $\bar{\tau}_{\Delta \nu}\left(S, S_{T}\right)$ is precomputed for a set of atmospheric levels $\left(s_{p}, p=1,2, \ldots N\right)$, with $N$ being approximately 30 . The $N$ levels are selected to yield approximately equal increments of $\Delta \tau$. The vertical layer mesh usually varies from 0.5 to $4 \mathrm{~km}$ with the smaller layers being concentrated near the lower surface. The emergent spectrum for each $\Delta \nu=0.1 \mathrm{~cm}^{-1}$ interval is computed from Equation (17) for $\Delta \mathrm{s}^{\prime}=0.1 \mathrm{~km}$ steps with the average transmittance obtained by interpolation from the precomputed transmittance array, $\bar{\tau}_{\Delta \nu}\left(\mathrm{s}_{\mathrm{p}}, \mathrm{S}_{\mathrm{T}}\right)$. Computing the average transmittance on a coarse vertical scale is essential for making the direct integration calculations tractable.

In order to compare the theoretical outgoing radiances with measured radiances $\left(\overline{\mathrm{N}}_{\nu_{\mathrm{n}}}\right)$, we must convolve the theoretical radiances with the instrument function, $f\left(\left|\nu-\nu_{n}\right|, a\right)$,

$$
\overline{\mathrm{N}}_{\nu_{\mathrm{n}}}=\int_{-\infty}^{+\infty} \mathrm{f}\left(\left|\nu-\nu_{\mathrm{n}}\right|, \mathrm{a}\right) \mathrm{N}_{\nu}\left(\mathrm{S}_{\mathrm{T}}\right) \mathrm{d} \nu .
$$

This convolution is accomplished by a fast Fourier transform procedure in the same manner as described for the homogenous path convolution. 
The numerical algorithm for determining the emergent radiances incorporates the following steps:

(1) Specify atmospheric model, vertical temperature profile, vertical gas concentration, and surface pressure

(2) Specify molecular absorbing gases and appropriate line parameters

(3) Set up vertical matrix of atmospheric temperatures, atmospheric effective pressures, and optical path lengths for each absorbing gas for each atmospheric layer

(4) Determine the average transmittance for a $0.1 \mathrm{~cm}^{-1}$ interval for $\mathrm{J}$ atmospheric levels from Equations (13) and (14)

(5) Determine the emergent radiance for each $0.1 \mathrm{~cm}^{-1}$ interval from Equation (17) across the spectral region of interest

(6) Determine the emergent radiance averaged over the instrument function as specified in Equation (18), for comparison to the observed spectrum. This algorithm has been programmed entirely in FORTRAN IV for an IBM 360 operating system.

\section{MONOCHROMATIC MOLECULAR ABSORPTION COEFFICIENT FORMULATION}

In this section we will describe the determination of the monochromatic molecular absorption coefficient at the $\nu_{k \ell}$ wave number mesh points necessary for the monochromatic transmittances. 
A molecular absorption line can be described by four parameters: line position $\left(\nu_{0}\right)$, integrated line intensity (S), relative line shape (b), and line halfwidth (a). The absorption coefficient for a single line is

$$
\ell_{\nu}=\mathrm{Sb}\left(\nu-\nu_{0}, \alpha\right)
$$

where the relative line shape $b\left(\nu-\nu_{0}, \alpha\right)$ depends on the type of line-broadening mechanism considered.

The two line shapes of importance in the terrestrial atmosphere are the thermal Doppler

$$
\mathrm{b}\left(\nu-\nu_{0}, \alpha_{\mathrm{D}}\right)=\frac{\sqrt{\ln 2}}{\alpha_{\mathrm{D}} \pi} \exp \left[\frac{-\left(\nu-\nu_{\mathrm{D}}\right)^{2} \ln 2}{\alpha_{\mathrm{D}}^{2}}\right]
$$

and the collision-broadened Lorentz

$$
\mathrm{b}\left(\nu-\nu_{0}, \alpha_{\mathrm{C}}\right)=\frac{\alpha_{\mathrm{C}}}{\pi} \frac{1}{\left(\nu-\nu_{0}\right)^{2}+\alpha_{\mathrm{C}}{ }^{2}}
$$

with $\alpha_{D}$ and $\alpha_{C}$ being the Doppler and collisional line half-widths, respectively. The mixed Lorentz-Doppler line shape is

$$
\mathrm{b}(\mathrm{a}, \mathrm{u})=\sqrt{\frac{\ln 2}{\pi}} \frac{1}{\alpha_{\mathrm{D}}} \mathrm{H}(\mathrm{a}, \mathrm{u})
$$

where $a=\left(\alpha_{C} / \alpha_{D}\right) \sqrt{\ln 2}$ and $u=\left[\left(\nu-v_{0}\right) / \alpha_{D}\right] \sqrt{\ln 2}$. The function $H(a, u)$ has been evaluated following a numerical scheme of YOUNG ${ }^{(19)}$. Kinetic theory predicts the temperature and pressure dependence of the collisional half-width 
to be

$$
\alpha_{C}(P, T)=\alpha_{C}\left(P_{r}, T_{r}\right) \frac{P}{P_{r}}\left(\frac{T_{r}}{T}\right)^{\gamma}
$$

with $\gamma=0.5$. The subscripts $r$ refer to reference conditions. For a mixture of gases, the pressure $P$ is usually converted to an effective pressure, $\left(P_{e}\right)$,

$$
P_{e}=P+(B-1) P_{a}
$$

to correct for the influence of self-broadening on the line half-width. The partial pressure of the absorbing gas is $P_{a}$ and $B$ is the self-broadening coefficient. The collisional line half-width now may be written as

$$
\alpha_{C}\left(P_{e}, T\right)=\alpha_{C}\left(P_{r}, T_{r}\right) \frac{P_{e}}{P_{r}}\left(\frac{T_{r}}{T}\right)^{\gamma}
$$

The molecular absorption coefficient at a specific wave number is the summation of the contribution from each of the individual molecular absorption lines, $\ell_{\nu_{\mathrm{m}}}$

$$
\mathrm{k}_{\nu}(\mathrm{P}, \mathrm{T})=\sum_{\mathrm{m}} \ell_{\nu_{\mathrm{m}}}(\mathrm{P}, \mathrm{T})=\sum_{\mathrm{m}} \mathrm{S}_{\mathrm{m}}(\mathrm{T}) \mathrm{b}\left(\nu-\nu_{0}, \alpha_{\mathrm{m}}(\mathrm{P}, \mathrm{T})\right) .
$$

For planetary atmospheres the monochromatic absorption coefficient varies by orders of magnitude on a scale of $1 / 1000 \mathrm{~cm}^{-1}$ for wave numbers near the line center, while in the line wings the absorption coefficient changes much more gradually. To retain a high degree of accuracy in the transmittance computations, the rapidly varying behavior of the absorption coefficient requires a wave number mesh spacing of the order $1 / 1000 \mathrm{~cm}^{-1}$ near the line center, while 
$1 / 10 \mathrm{~cm}^{-1}$ will suffice in the line wings. The method used to evaluate Equation (26) is patterned after the numerical technique developed by DRAYSON ${ }^{(8)}$. Basic to this procedure are a division of each line into direct and wing contributions and the establishment of a variable wave number mesh for the evaluation of $\mathrm{k}_{\nu}(\mathrm{P}, \mathrm{T})$.

The direct contribution includes all wave numbers within a distance $\delta$ of the line center, and the wing contribution includes all wave numbers equal to or greater than $\delta$,

$$
\ell_{\nu}=\underset{\Delta \nu<\delta}{\ell^{\mathrm{D}}}+\underset{\Delta \nu \geqslant \delta}{\ell^{\mathrm{W}}}
$$

where $\delta$ has been chosen as $3.5 \mathrm{~cm}^{-1}$. The total molecular absorption coefficient now becomes

$$
\mathrm{k}_{\nu}\left(\mathrm{P}_{\mathrm{e}}, \mathrm{T}\right)=\sum_{\mathrm{m}} \ell_{\mathrm{m}}^{\mathrm{D}}\left(\mathrm{P}_{\mathrm{e}}, \mathrm{T}\right)+\sum_{\mathrm{m}} \ell_{\mathrm{m}}^{W}\left(\mathrm{P}_{\mathrm{e}}, \mathrm{T}\right)
$$

which can be rewritten

$$
\mathrm{k}_{\nu}\left(\mathrm{P}_{\mathrm{e}}, \mathrm{T}\right)=\mathrm{k}_{\nu}^{\mathrm{D}}\left(\mathrm{P}_{\mathrm{e}}, \mathrm{T}\right)+\mathrm{k}_{v}^{\mathrm{W}}\left(\mathrm{P}_{\mathrm{e}}, \mathrm{T}\right)
$$

with

$$
\begin{array}{ll}
\mathrm{k}_{\nu}^{\mathrm{W}}\left(\mathrm{P}_{\mathrm{e}}, \mathrm{T}\right)=\sum_{\mathrm{m}} \ell_{\mathrm{m}}^{\mathrm{W}}\left(\mathrm{P}_{\mathrm{e}}, \mathrm{T}\right) & |\Delta \nu| \geqslant \delta \\
\mathrm{k}_{\nu}^{\mathrm{D}}\left(\mathrm{P}_{\mathrm{e}}, \mathrm{T}\right)=\sum_{\mathrm{m}} \ell_{\mathrm{m}}^{\mathrm{D}}\left(\mathrm{P}_{\mathrm{e}}, \mathrm{T}\right) . & |\Delta \nu|<\delta
\end{array}
$$


The technique of separating each line into direct and wing contributions has the advantage that one need consider only lines in the interval $v-\delta$ to $\nu+\delta$, rather than all lines, for computing the direct contribution, thus insuring a considerable reduction in the amount of computer time required. A second advantage is that the wing contribution may be easily adjusted for empirical fitting to observed spectra in spectral regions where the theoretical treatment is not adequate. An example of this will be discussed later for the water vapor continuum in the 500 and $1000 \mathrm{~cm}^{-1}$ windows.

The determination of the wave number mesh for the direct contribution will be described briefly with the aid of Figure 2. Cases where no line, one line, and two lines fall within the $\Delta v=0.1 \mathrm{~cm}^{-1}$ interval are shown in Figure 2 (a), 2(b), and 2(c), respectively. The circled numbers indicate the subinterval number; the dashed lines, the subinterval boundaries; and the short lines near the bottom of each figure indicate schematically the wave number mesh. The wave number scale is distorted near the line centers for clarity of presentation. The distance $d_{1}$ from the line center is subdivided into subintervals, each containing four mesh points whose positions within the subinterval are specified by the Legendre-Gauss quadrature abscissa points. The distance $d_{1}$ is usually chosen as $0.01 \mathrm{~cm}^{-1}$ and the number of subintervals in $d_{1}$ is a variable in the range of from one to five with the higher number of subintervals yielding more accu rate transmittance values. The number of subintervals is usually taken as 
two, which allows the transmittances to be computed with a numerical accuracy of two to three significant figures, an accuracy which is sufficient for most applications. After the subintervals are established near the line center, the remaining sections of the interval, $d_{2}$ and $d_{3}$ in Figure $2(b), d_{2}, d_{3}$, and $d_{4}$ in Figure 2(c), are each assigned as one subinterval. For more than two lines in a $0.1 \mathrm{~cm}^{-1}$ interval the division scheme of Figure $2(\mathrm{c})$ is applied repeatedly. Without lines in the $0.1 \mathrm{~cm}^{-1}$ interval, the four-point Legendre-Gauss quadrature is applied to the entire $0.1 \mathrm{~cm}^{-1}$ interval. The scale of the variable wave number mesh is thus of the order $0.001-0.01 \mathrm{~cm}^{-1}$.

The mixed Doppler-Lorentz line shape is used in the direct contribution if the total pressure is less than $100 \mathrm{mb}$ and the distance from the line center is less than $0.2 \mathrm{~cm}^{-1}$. The Lorentz line shape is used for the remaining direct contribution.

The collisional line shape is applicable for the wing contribution which, from Equations (19), (21), and (30) and using the condition $\Delta_{\nu} \gg \alpha_{\mathrm{C}}\left(\mathrm{P}_{\mathrm{r}}, \mathrm{T}_{\mathrm{r}}\right)$

$$
\mathrm{k}_{\nu}^{\mathrm{W}}\left(\mathrm{P}_{\mathrm{e}}, \mathrm{T}\right)=\mathrm{k}_{\nu}^{0}(\mathrm{~T}) \frac{\mathrm{P}_{\mathrm{e}}}{\mathrm{P}_{\mathrm{r}}}
$$

with

$$
k_{\nu}^{0}(T)=\sum_{m} \frac{S_{m}(T) \alpha_{c_{m}}\left(P_{r}, T_{r}\right)}{\pi\left(\nu-\nu_{o_{m}}\right)^{2}}\left(\frac{T_{r}}{T}\right)^{\gamma}
$$


The function $\mathrm{k}_{\nu}^{0}(\mathrm{~T})$ changes slowly with respect to wave number and thus may be precomputed at a coarser wave number grid $\left(\sim 0.5 \mathrm{~cm}^{-1}\right)$ than required for the direct contribution with intermediate values obtained by interpolation.

From Equations (19), (29), and (31), the total monochromatic absorption coefficient necessary for determining the monochromatic transmittance for the $i$-th gas and $j$-th layer (see Equation 13) is

$$
k_{\nu_{k 1}}^{i j}\left(\bar{P}_{e}, \bar{T}_{j}\right)=\sum_{m} S\left(\bar{T}_{j}\right) b_{m}\left(\bar{P}_{e_{j}}, \bar{T}_{j}\right)+\left(k_{v_{k l}}^{0}\left(\bar{T}_{j}\right)\right) \frac{\bar{P}_{e_{j}}}{P_{r}} .
$$

The molecular line parameters for the evaluation of Equation (33) are stored on magnetic tape, ordered by ascending wave number, with the parameters $\nu_{0}$, Icode, $\alpha_{c}, \gamma, \mathrm{S}(175 \mathrm{~K}), \mathrm{S}(200 \mathrm{~K}), \ldots, \mathrm{S}(300 \mathrm{~K})$ preserved for each line and with Icode identifying the species of gas. The present atlas contains $\sim 6000$ $\mathrm{H}_{2} \mathrm{O}$ lines, $\sim 5000 \mathrm{O}_{3}$ lines, and $\sim 10,000$ lines of $\mathrm{CO}_{2}$ in the 200 to $2000 \mathrm{~cm}^{-1}$ range. The sources of these line parameters and the modifications for empirical line shapes are the subject of the next section.

\section{SOURCES FOR MOLECULAR TRANSMITTANCE PARAMETERS}

The molecular line parameters for carbon dioxide, water vapor, and ozone were collected from a variety of sources. The molecular parameters for $\mathrm{CO}_{2}$ are generated in the following manner. The line positions and strengths have been determined for 68 bands of $\mathrm{C}^{12} \mathrm{O}_{2}{ }^{16}$, using standard spectroscopic formulation for a linear molecule, from band center positions, energy levels, 
rotational constants, and band strengths provided by BENEDICT (20). The only exception is that the band intensities of DRAYSON (21) are used if significant differences exist. The band parameters for the stronger $\mathrm{C}^{12} \mathrm{O}_{2}{ }^{16}$ bands are listed in Table 1. Also included in the computations are 70 isotopic bands of carbon dioxide. The strengths of these bands relative to the corresponding bands of $\mathrm{C}^{12} \mathrm{O}_{2}{ }^{16}$ are taken to be the same as the abundance of the species relative to $\mathrm{C}^{12} \mathrm{O}_{2}{ }^{16}$. The relative abundances are calculated from the terrestrial abundances of the isotopes of carbon and oxygen.

The self- and nitrogen-broadened line half-widths for carbon dioxide as a function of rotational quantum number were obtained from YAMAMOTO et aI. (22), and were assumed to be valid for all vibrational bands.

The $\mathrm{CO}_{2}$ continuum is substantially sub-Lorentzian in the $1000 \mathrm{~cm}^{-1} \mathrm{re}-$ gion. BIGNELL et al. (23) have reported experimental work from which they concluded the absorption by $\mathrm{CO}_{2}$ outside the range from 560 to $790 \mathrm{~cm}^{-1}$ is negligible. WINTERS (24), following suggestions by BENEDICT, found that an exponential modification of the Lorentz line shape beyond some minimum distance from the line center improved the agreement of calculated and experimental absorptance for $\mathrm{CO}_{2}$ in the $2400 \mathrm{~cm}^{-1}$ region. Recently, BIRNBAUM (25) has developed a theoretical basis for a line shape which is Lorentzian near the line center and exponential sufficiently far from the line center. The point at which the shape becomes exponential depends on the duration of collision. 
BURCH ${ }^{(26)}$ has found that the wings of nitrogen-broadened $\mathrm{CO}_{2}$ lines absorb only about 1 percent as much in the $780-900 \mathrm{~cm}^{-1}$ regions as if they had the Lorentz shape. To fit the experimental $\mathrm{CO}_{2}$ continuum we have assumed an exponential modification of the Lorentz line shape

$$
\begin{array}{ll}
\mathrm{b}=\mathrm{b}_{\text {Lorentz }} & \left|\nu-\nu_{0}\right| \leqslant \nu_{\text {min }} \\
\mathrm{b}=\mathrm{b}_{\text {Lorentz }} \exp \left[-\mathrm{a}\left(\left|\nu-\nu_{0}\right|-\nu_{\text {min }}\right)^{\mathrm{b}}\right] & \left|\nu-\nu_{0}\right|>\nu_{\text {min }}
\end{array}
$$

beyond $\nu_{\min }=3.5 \mathrm{~cm}^{-1}$ from the line center for all $\mathrm{CO}_{2}$ lines in the 500 to 800 $\mathrm{cm}^{-1}$ region. The parameters a and b have been calculated using WINTERS' et al. (24) values $a=0.08$ and $b=0.8$ as starting values and running a mesh of $a^{\prime} s$ and $b^{\prime} s$ to find the parameters which reproduce the experimental continuum absorption. The best fit is obtained with $a=1.4$ and $b=0.25$. The above exponential correction was also used for the $\mathrm{CO}_{2}$ continuum in the $500 \mathrm{~cm}^{-1}$ window region. A fit to the self-broadened $\mathrm{CO}_{2}$ continuum of $\mathrm{BURCH}{ }^{(26)}$ yields values of $\mathrm{a}$ and $\mathrm{b}$ approximately the same as the nitrogen-broadened continuum values.

The accuracy of the theoretical calculations was checked by computing the transmission for various homogenous path pressures and optical masses and comparing with published experimental spectra (BURCH et al. ${ }^{(27)}$ ). Two of these cases are shown in Figure 3, with the theoretical transmission being computed with a triangular instrument function of $4 \mathrm{~cm}^{-1}$ full width at halfmaximum. The solid line represents the measurcment, and the dashed line, the calculation. The agreement is better than 10 percent for both cases. The 
errors in the strong Q-branch regions are enhanced by imprecise knowledge of the true instrument function and do not reflect a major discrepancy between the theoretical and experimental transmittances. However, the theoretical computations need improvement for the pressure-broadened line shape within $5 \mathrm{~cm}^{-1}$ from the line center. The investigations of BURCH et al. ${ }^{(28)}$ have indicated significant deviations from the Lorentz shape for self-broadened $\mathrm{CO}_{2}$ lines in the 2400,3800 , and $7000 \mathrm{~cm}^{-1}$ regions. Experimental investigations are needed to determine the deviation for $\mathrm{N}_{2}-\mathrm{CO}_{2}$ and $\mathrm{CO}_{2}-\mathrm{CO}_{2}$ collisions for the $667 \mathrm{~cm}^{-1}$ band.

The line data used for water vapor are taken from BENEDICT and KAPLAN ${ }^{(29)}$ for the pure rotational lines and from BENEDICT and CALFEE ${ }^{(30)}$ for the $1595 \mathrm{~cm}^{-1}$ band.

One of the most difficult problems to treat in atmospheric transmission models is the water vapor continuum regions. The difficulties arise because of uncertainties in the effect of aerosols, in knowledge of molecular line shapes in the far wings of lines, and in knowledge of the physical mechanisms responsible for the water vapor absorption. Water vapor continuum absorption in the 500 $\mathrm{cm}^{-1}$ and $1000 \mathrm{~cm}^{-1}$ windows was discussed in the Nimbus 3 IRIS paper (CONRATH et al. ${ }^{(31)}$ ). The water vapor continuum absorption coefficients adopted for the Nimbus 3 investigation gave good agreement in the $1000 \mathrm{~cm}^{-1}$ window, but overestimated the absorption in the $500 \mathrm{~cm}^{-1}$ window. 
Since the publication of Reference 31, a number of pertinent laboratory and free atmosphere investigations concerning water vapor continuum absorption have been published. Laboratory measurements by BIGNELL ${ }^{(32)}$ and BURCH ${ }^{(26)}$ indicate the water vapor continuum absorption in the $500 \mathrm{~cm}^{-1}$ and $1000 \mathrm{~cm}^{-1}$ regions consists of two components, one proportional to the total pressure and the other to the water-vapor partial pressure:

$$
k\left(P, P_{H_{2}}^{\prime} \mathrm{O}, T\right)=k_{1}(T) P+k_{2}(T) P_{\mathrm{H}_{2} \mathrm{O}}
$$

BIGNELL ${ }^{(32)}$ has also reinterpreted, in a semiquantitative sense, previous atmospheric and laboratory measurements in these spectral regions and concludes that the previous work in general substantiates the two-component mechanism. Recent interpretations of atmospheric measurements by PLATT, $(33,34)$ WARK, ${ }^{(35)}$ and HOUGHTON and LEE ${ }^{(36)}$ have further verified the Bignell and Burch results.

The two-component continuum has been incorporated in the transmittance model; the adopted $\mathrm{k}_{1}$ and $\mathrm{k}_{2}$ values are illustrated in Figure 4. Laboratory values of $\mathrm{k}_{1}$ in the $1000 \mathrm{~cm}^{-1}$ regions are not available due to experimental difficulties. The laboratory values of Burch for this region shown in Figure 4 represent only the upper limits to $\mathrm{k}_{1}$. The investigations of WARK (35) and HOUGHTON and LEE ${ }^{(36)}$ gave satisfactory results with the $k_{1}$ value in the $1000 \mathrm{~cm}^{-1}$ window essentially zero. Based on their success, we have forced $\mathrm{k}_{1}$ to approximately zero by extrapolation of the measured $\mathrm{k}_{1}$ component from 
the $500 \mathrm{~cm}^{-1}$ window region and of the computed Lorentz foreign-broadened wing component of the $1595 \mathrm{~cm}^{-1} \mathrm{H}_{2} \mathrm{O}$ band. The $\mathrm{k}_{1}$ and $\mathrm{k}_{2}$ components at $175 \mathrm{~K}$ were scaled from the $300 \mathrm{~K}$ values using the temperature dependence of Bignell.

Also shown in Figure 4 is the wing contribution of the rotational water-vapor lines using the modified Van Vleck-Weisskopf (M-VVW) line shape described by FARMER (37). All self-broadened components have been computed for a self-broadening coefficient of 6.3. As illustrated in Reference 31, no theoretical line shape is adequate for the $500 \mathrm{~cm}^{-1}$ and $1000 \mathrm{~cm}^{-1}$ window regions. However, M-VVW line shape gives fair agreement with the measurements of PALMER ${ }^{(38)}$ in the $250-350 \mathrm{~cm}^{-1}$ range and, for continuity, the adopted $\mathrm{k}_{1}$ and $\mathrm{k}_{2}$ components are normalized to the $\mathrm{M}-\mathrm{VVW}$ at $400 \mathrm{~cm}^{-1}$. The Lorentz line shape is used for the $1595 \mathrm{~cm}^{-1} \mathrm{H}_{2} \mathrm{O}$ band with the normalization to $\mathrm{k}_{1}$ and $\mathrm{k}_{2}$ occurring at $1400 \mathrm{~cm}^{-1}$. The normalization results in slight discontinuities, which, however, create no problems in practice. The water vapor continuum absorption in the 400 to $1400 \mathrm{~cm}^{-1}$ range thus is based on laboratory data computed from Equation (35) with the $\mathrm{k}_{1}$ and $\mathrm{k}_{2}$ values determined numerically. For water vapor in this region, Equation (35) replaces the term $k_{\nu}^{w}\left(P_{e}, T\right)$ of Equation (29).

The adopted water vapor continuum absorption coefficients are employed in the transmittance model in an empirical sense, to be used as part of a working model until more knowledge is acquired of the opacity sources and their 
governing physical mechanisms. While the empirical model may still need considerable adjustment with regard to the actual numerical magnitudes of $k_{1}$ and $k_{2}$, it is felt that the two-component concept, especially the $\mathrm{p}_{\mathrm{H}_{2} \mathrm{O}}$ term, is an important step forward in coping with water vapor continuum transmittance problems.

Homogenous path comparisons for the $1595 \mathrm{~cm}^{-1} \mathrm{H}_{2} \mathrm{O}$ band are shown in Figure 5. The experimental data of $\mathrm{BURCH}$ et al. (27) varied in spectral resolution from $\sim 5 \mathrm{~cm}^{-1}$ at $1200 \mathrm{~cm}^{-1}$ to $\sim 20 \mathrm{~cm}^{-1}$ at $2000 \mathrm{~cm}^{-1}$. Thus the $\mathrm{R}$ branch side of the band does not exhibit much line structure. The agreement in the P and $\mathrm{R}$ branches is better than 5 percent, with the theoretical transmittances being slightly too transparent in the continuum.

The first-generation ozone line parameters was not very satisfactory, as evidenced in the radiance comparisons of Reference 31. A second-generation set of ozone lines is now available; the main improvement is the inclusion of numerous upper-state bands. This line set seems to be more satisfactory based on comparisons to balloon flight measurements by GOLDMAN et al. (39) and to laboratory data by AIDA (40). Included in this line set is the $\nu_{2}$ band at $701.4 \mathrm{~cm}^{-1}$, a band which is of importance to atmospheric temperature inversions in the $667 \mathrm{~cm}^{-1} \quad \mathrm{CO}_{2}$ band region. Theoretical calculations for this band are compared to the laboratory spectra of MCCAA and SHAW ${ }^{(41)}$ in Figure 6. The number of lines considered for the $\nu_{2}$ band was 2158, with a collisional 
half-width of $0.07 \mathrm{~cm}^{-1}$ at $296 \mathrm{~K}$ and a Lorentz line-shape. Self-broadening. effects were assumed to be unimportant. The general agreement is approximately 5 to 10 percent which is satisfactory for initial applications to the temperature inversion problem. Absorption by these lines is demonstrated for a slant path in the paper on application to the Nimbus 4 IRIS spectra (KUNDE (15)).

\section{CONCLUDING REMARKS}

A direct integration transmittance model has been developed for interpretation of spectra of intermediate to high spectral resolution recorded in the laboratory or in the atmosphere. This procedure, though time-consuming on present digital computers, avoids limitations and approximations necessary when employing empirical representations and band models for computation of molecular absorption. The main advantages of the direct integration technique are the ability to attain high spectral resolution and to easily vary this resolution; to facilitate different types of line shapes readily, including mixed line shapes; to handle line wing effects; to cope with temperature, pressure, and gas concentration variations, and to avoid assumptions necessary to reduce a slant path absorption to the equivalent homogenous path absorption. The central concepts for making the direct integration a tractable problem are the variable wave number mesh and the division of each line into direct and wing contributions. As the numerical procedures are essentially exact, the accuracy of the predicted transmittances is limited by the accuracy of the input molecular parameters. 
As a consistency check on the input line parameters and the transmittance model, theoretical predictions have been compared to existing laboratory data for several representative homogenous path cases. The comparisons gave transmittance disagreements of 5 to 10 percent, a number which is probably indicative of the absolute accuracy of present state-of-the-art molecular transmittances.

The accuracy of the slant path model and the predicted transmittances has been assessed by comparison to Nimbus 4 IRIS data, and Mariner 9 IRIS data, with both applications yielding agreements of 5 to 10 percent in emergent radiances through the 200 to $2000 \mathrm{~cm}^{-1}$ region. The model is presently being tested further against high spectral resolution terrestrial transmittance spectra $\left(\sim 0.2 \mathrm{~cm}^{-1}\right)$ and downward sky emission spectra in the 450 to $1400 \mathrm{~cm}^{-1} \mathrm{re}-$ gion obtained from McDonald and Mauna Kea Observatory.

\section{ACKNOW LEDGMENTS}

We would like to thank Dr. W. S. Benedict, University of Maryland, and Dr. S. R. Drayson, University of Michigan, for providing the $\mathrm{CO}_{2}$ energy levels, rotational constants, and band intensities. We are also indebted to Dr. Drayson for numerous discussions concerning the direct integration technique and to Dr. R. Hanel for suggestions in improving the manuscript. Programming the convolution of the monochromatic spectrum with the instrument function using fast Fourier transform techniques was accomplished by L. Herath, Goddard Space Flight Center. 


\section{REFERENCES}

1. R. A. Hanel, B. J. Conrath, V. G. Kunde, C. Prabhakara, I. Revah, V. V. Salomonson, and G. Wolford, JGR, 77, 2629 (1972).

2. J. Connes, P. Connes, and J. P. Maillard, "Atlas des spectres dans le proche infrarouge de Venus, Mars, Jupiter et Saturne," Centre National de la Recherche Scientifique, Paris (1969).

3. R. A. Hanel, V. G. Kunde, T. Meilleur, and G. Stambach, Planetary Atmospheres. C. Sagan, ed., Reidel (1971).

4. D. M. Rank, private communication (1972).

5. R. A. Hanel, B. Conrath, W. Hovis, V. Kunde, P. Lowman, W. Maguire, J. Pearl, J. Pirraglia, C. Prabhakara, B. Schlachman, G. Levin, P. Straat, and T. Burke, Icarus, 17, 423 (1972).

6. P. Connes, J. Connes, R. Bouigue, M. Querci, J. Chauville, and F. Querci, Annales d'Astrophysique, Tome 31, Fascicule 5 (1968).

7. T. R. Geballe, E. R. Wollman, and D. M. Rank, Ap. J. Letters, 177, L27 (1972).

8. S. R. Drayson, Appl . Opt. , 5, 385 (1966).

9. T. G. Kyle, JQSRT, 9, 1477 (1969). 
10. V. G. Kunde, Ap. J., 153, 435 (1968).

11. J. R. Auman, Ap. J. Suppl., 14, 171 (1967).

12. F. Querci, M. Querci, and V. G. Kunde, Astron. \& Astrophys., 15, 256 (1971).

13. R. F. Calfee, JQSRT, $\underline{6}, 221$ (1966).

14. J. O. Arnold, E. E. Whiting, and G. C. Lyle, JQSRT, 9, 775 (1969).

15. V. G. Kunde, B. J. Conrath, R. A. Hanel, W. C. Maguire, C. Prabhakara, and V. V. Salomonson, JGR, to be published (1973).

16. A. H. Stroud and D. Secrest, "Gaussian Quadrature Formulas," Prentice-Hall, Inc., Englewood Cliffs, N. J. (1966).

17. J. W. Brault and O. R. White, Astron. \& Astrophys., 13, 169 (1971).

18. V. G. Kunde, NASA TN D-4045, August (1967).

19. C. Young, JQSRT, $\underline{5}, 549$ (1965).

20. W. S. Benedict, private communication (1971).

21. S. R. Drayson, "Proceedings of Conference on Atmospheric Radiation," Colorado State University, Fort Collins, Colorado, August 7-9, (1972).

22. G. Yamamoto, M. Tanaka, and T. Aoki, JQSRT, 9, 371 (1969).

23. K. Bignell, F. Saiedy, and P. A. Sheppard, JOSA, 53, 466 (1963).

24. B. H. Winters, S. Silverman, and W. S. Benedict, JQSRT, $\underline{4}, 527$ (1964). 
25. G. Birnbaum, "The Shape of Collision Broadened Lines Near Resonance and in the Far Wings, " to be published (1973).

26. D. E. Burch, Philco-Ford Corporation Aeronautronic Division Publication U-4784, January 31, (1970).

27. D. E. Burch, D. Gryvnak, E. B. Singleton, W. L. France, and D. Williams, AFCRL-62-698, July (1962).

28. D. E. Burch, D. A. Gryvnak, R. R. Patty, and C. E. Bartky, JOSA, $\underline{59}, 267(1969)$.

29. W. S. Benedict and L. D. Kaplan, private communication (1967).

30. W. S. Benedict and R. F. Calfee, ESSA Prof. Paper 2, June (1967).

31. B. J. Conrath, R. A. Hanel, V. G. Kunde, and C. Prabhakara, JGR, $\underline{75}, 5831(1970)$.

32. K. J. Bignell, QJRMS, 96, 390 (1970).

33. C. M. R. Platt, NATURE, 235, 29 (1972).

34. C. M. R. Platt, JGR, 77, 1597 (1972).

35. D. Q. Wark, "Proceedings of International Radiation Symposium," Sendai, Japan, May 26 - June 2, (1972).

36. J. T. Houghton and A. C. L. Lee, NATURE, 238, 117 (1972).

37. C. B. Farmer, E. M. I. Ltd. Rep. DMP 2780, Hayes, Middlesex, England, April (1967). 
38. C. H. Palmer, JOSA, 47, 1024 (1957).

39. A. Goldman, T. G. Kyle, D. G. Murcray, F. H. Murcray, and W. J. Williams, Appl. Opt. , $\underline{9}, 565$ (1970).

40. Masaru Aida, "Proceedings of International Radiation Symposium," Sendai, Japan, May 26 - June 2, (1972).

41. D. J. McCaa and J. H. Shaw, AFCRL-67-0237, February (1967). 
Table 1

Line Parameters and Band Intensities for the Strongest $\mathrm{C}^{12} \mathrm{O}_{2}{ }^{16}$ Bands at $300 \mathrm{~K}$.

\begin{tabular}{|c|c|c|c|c|c|c|}
\hline \multirow[b]{2}{*}{ Band No. } & \multicolumn{2}{|c|}{ Level } & \multirow[b]{2}{*}{$\begin{array}{c}\text { Lower State } \\
\text { Energy } \\
\left(\mathrm{cm}^{-1}\right)\end{array}$} & \multirow[b]{2}{*}{$\begin{array}{l}\text { Band Center } \\
\left(\mathrm{cm}^{-1}\right)\end{array}$} & \multicolumn{2}{|c|}{ Band Intensity ${ }^{*}$} \\
\hline & Lower & Upper & & & $\mathrm{cm}^{-1}(\mathrm{~atm} \mathrm{~cm})^{-1} 300 \mathrm{~K}$ & $\mathrm{~cm}^{-1}(\mathrm{~mol} \mathrm{~cm}-2)$ \\
\hline 1 & $\left(10^{0} 0,02^{0} 0\right)_{I} 1000$ & $0301\left(11^{1} 0,03^{1} 0\right)_{\Pi}$ & 1388.187 & 544.283 & $0.10^{\mathrm{b}}$ & $2.4 \times 10^{-22}$ \\
\hline 2 & $\left(11^{3} 0,03^{3} 0\right) \Pi^{0303}$ & $0402\left(12^{2} 0,04^{2} 0\right)$ & 2003.309 & 581.697 & $0.0084^{\mathrm{b}}$ & $1.5 \times 10^{-22}$ \\
\hline 3 & 0202 & $0301\left(11^{1} 0,03^{1} 0\right) \pi$ & 1335.129 & 597.341 & 0.14 & $3.4 \times 10^{-21}$ \\
\hline 4 & 0101 & $0200\left(10^{0} 0,02^{0} 0\right) \mathrm{II}$ & 667.379 & 618.033 & 4.27 & $1.43 \times 10^{-19}$ \\
\hline 5 & $\left(10^{0} 0,02^{0} 0\right) \mathrm{II}^{0200}$ & $0301\left(11^{1} 0,03^{1} 0\right)_{H}$ & 1285.412 & 647.058 & $0.591^{b}$ & $1.48 \times 10^{-20}$ \\
\hline 6 & 0000 & 0101 & 0.0 & 667.379 & 194.0 & $8.93 \times 10^{-18}$ \\
\hline 7 & 0101 & 0202 & 667.379 & 667.750 & 15.0 & $5.03 \times 10^{-19}$ \\
\hline 8 & $\begin{array}{l}0202 \\
0\end{array}$ & $0303\left(11^{3} 0,03^{3} 0\right)_{\Pi}$ & 1335.129 & 668.180 & 0.85 & $2.1 \times 10^{-20}$ \\
\hline 9 & $\left(10^{0} 0,02^{0} 0\right) \mathrm{I}$ & $1101\left(11^{1} 0,03^{1} 0\right)_{I}$ & 1388.187 & 688.678 & 0.3 & $7.0 \times 10^{-21}$ \\
\hline 10 & 0101 & $1000\left(10^{0} 0,02^{0} 0\right)_{I}$ & 667.379 & 720.808 & 5.0 & $1.7 \times 10^{-19}$ \\
\hline 11 & $\left(11^{1} 0,03^{1} 0\right)_{\pi} 0301$ & $1200\left(12^{0} 0,04^{0} 0\right) \mathbf{I}$ & 1932.470 & 738.643 & $0.00832^{b}$ & $1.53 \times 10^{-22}$ \\
\hline 12 & 0202 & $1101\left(11^{1} 0,03^{1} 0\right)_{I}$ & 1335.139 & 741.736 & $0.144^{b}$ & $3.52 \times 10^{-21}$ \\
\hline 13 & $\left(11^{3} 0,03^{3} 0\right) \Pi^{0303}$ & $1202\left(12^{2} 0,04^{2} 0\right)_{\mathrm{T}}$ & 2003.309 & 757.426 & $0.009^{\mathrm{b}}$ & $2.0 \times 10^{-22}$ \\
\hline 14 & $\left(10^{0} 0,02^{0} 0\right) \mathrm{II}^{0200}$ & $1101\left(1,1^{1} 0,03^{1} 0\right)_{I}$ & 1285.412 & 791.453 & 0.022 & $5.5 \times 10^{-22}$ \\
\hline 15 & $\left(11^{1} 0,03^{1} 0\right)_{\Pi}^{0301}$ & $1202\left(12^{2} 0,04^{2} 0\right)_{\mathrm{I}}$ & 1932.470 & 828.265 & $0.00039^{b}$ & $7.2 \times 10^{-24}$ \\
\hline 16 & $\left(10^{0} 0,02^{0} 0\right)$ I 1000 & 0010 & 1388.187 & 960.955 & $0.0184^{b}$ & $4.38 \times 10^{-22}$ \\
\hline 17 & $\left(10^{0} 0,02^{0} 0\right) \Pi^{0200}$ & 0010 & 1285.412 & 1063.730 & $0.244^{b}$ & $6.10 \times 10^{-22}$ \\
\hline
\end{tabular}

*The superscript $b$ indicates the band intensity is from W. S. BENEDICT, ${ }^{(20)}$ the remaining intensities are from DRAYSON ${ }^{(21)}$. 


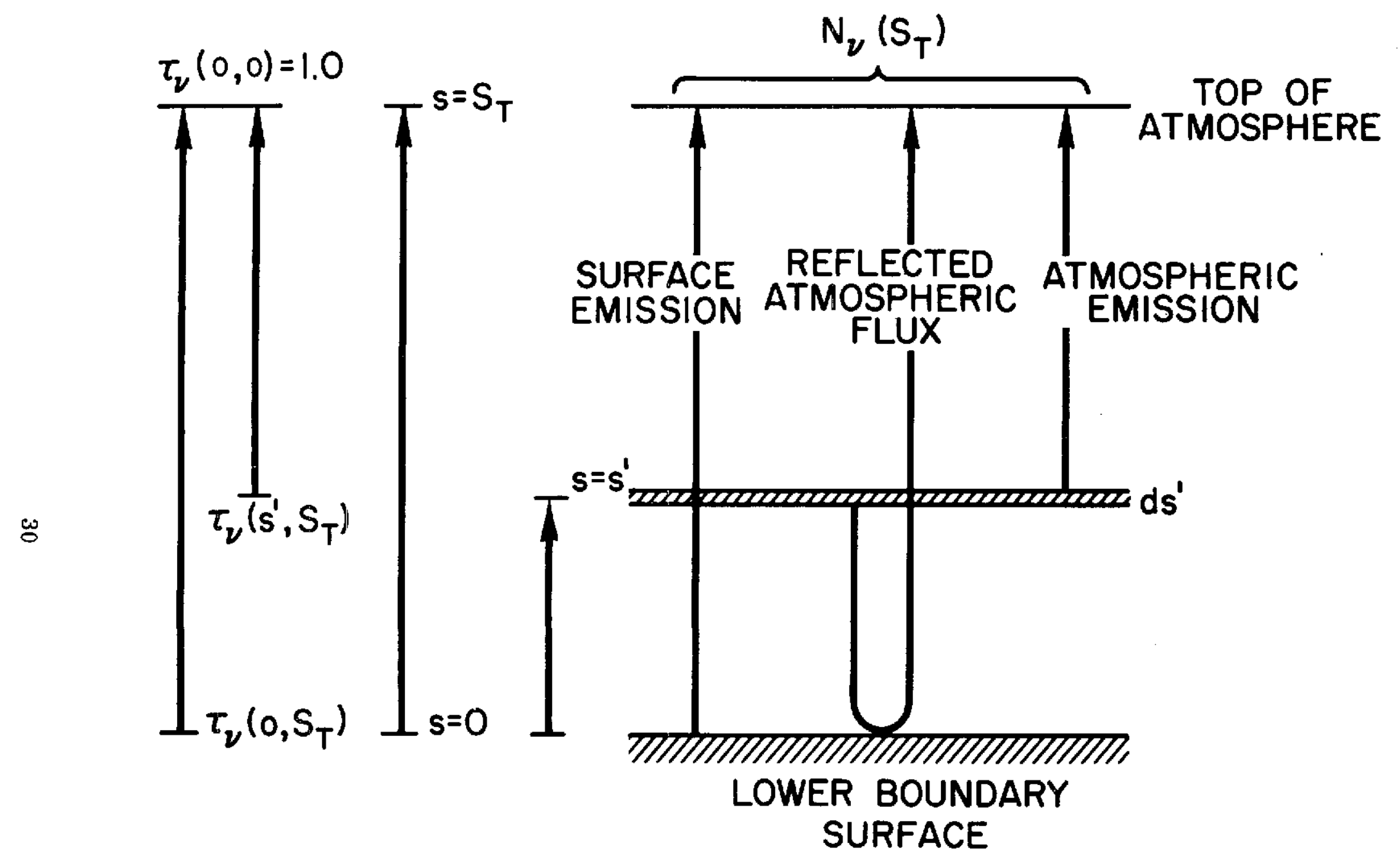

Figure 1. Schematic of radiation components contributing to emergent radiation field at top of the atmosphere. 


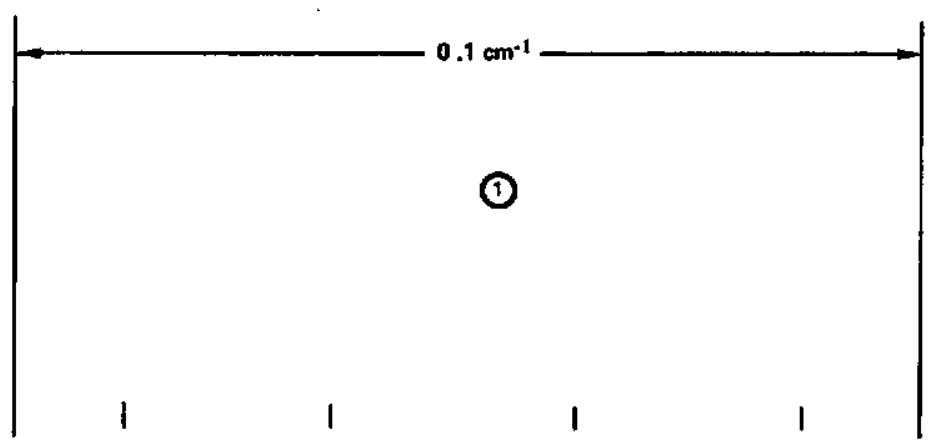

(a)

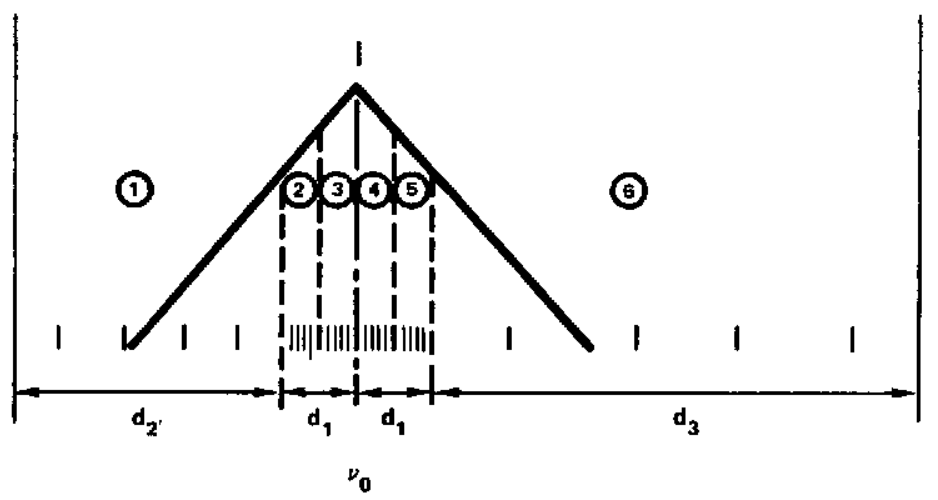

(b)

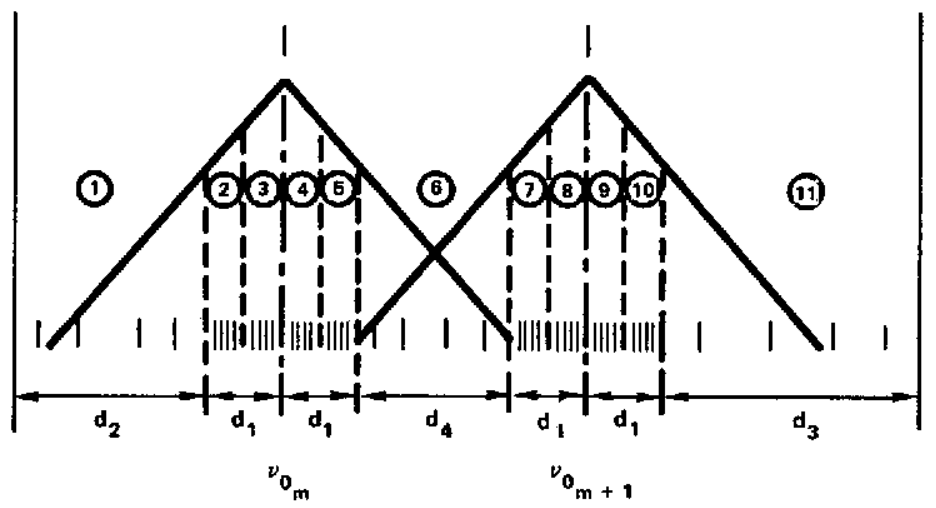

(c)

Figure 2. Schematic of variable wave number mesh for $0.1 \mathrm{~cm}^{-1}$ interval with two sub-intervals in $d_{1}$. a) no molecular lines, 4 mesh points, b) one molecular line, 6 sub-intervals, 24 mesh points, c) two molecular lines, 11 sub-intervals, 44 mesh points. 

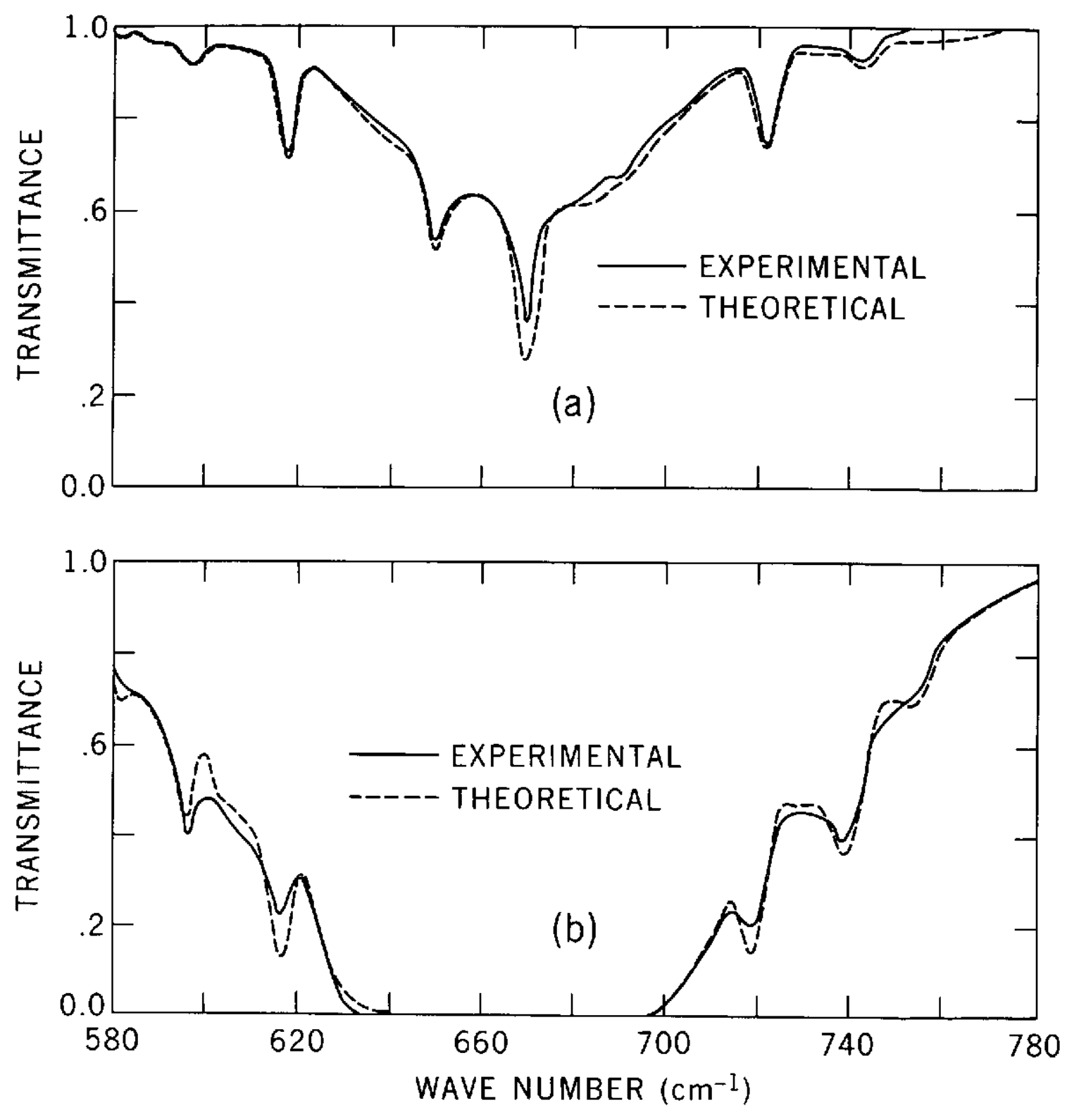

Figure 3. Homogenous path comparison for $667 \mathrm{~cm}^{-1} \mathrm{CO}_{2}$ band at room temperature: a) $\mathrm{P}_{\mathrm{e}}=02053 \mathrm{~atm}$, $\mathrm{u}=6.30 \mathrm{~cm}$ atm; b) $P_{\mathrm{e}}=.0857 \mathrm{~atm}, \mathrm{u}=212.1 \mathrm{~cm}$ atm. 


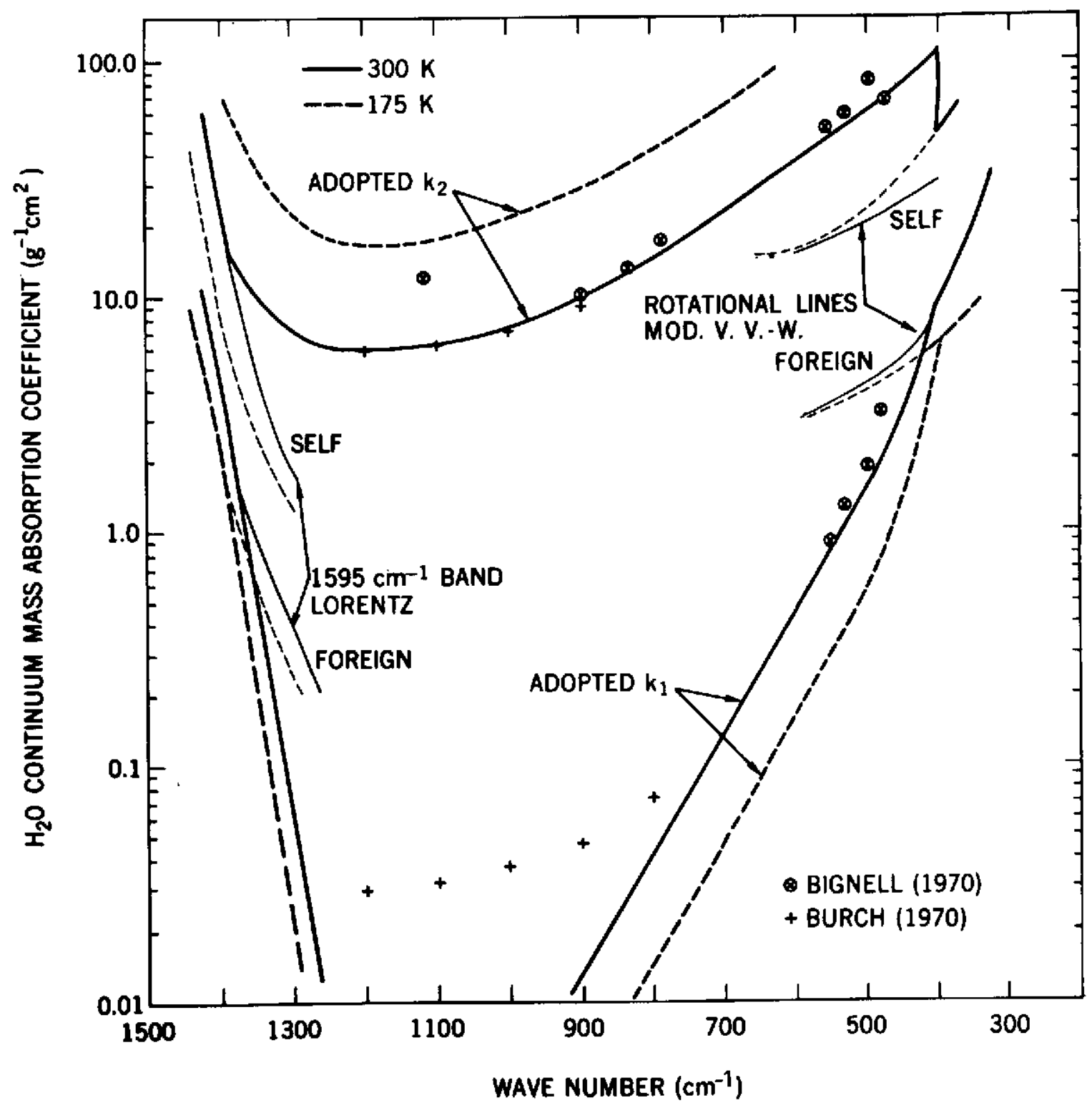

Figure 4. Water vapor continuum absorption coefficient for the $400-1400 \mathrm{~cm}^{-1}$ region. The $\mathrm{k}_{2}$ component is normalized to the self-broadened Modified Van Vleck-Weisskopf line shape for the rotational $\mathrm{H}_{2} \mathrm{O}$ lines at $400 \mathrm{~cm}^{-1}$ and the self-broadened Lorentz line shape for the lines of the $1595 \mathrm{~cm}^{-1} \mathrm{H}_{2} \mathrm{O}$ band at $1400 \mathrm{~cm}^{-1}$. The $k_{1}$ component is normalized in a similar manner to the foreign broadened water vapor components at 400 and at $1400 \mathrm{~cm}^{-1}$. Only the $k_{1}$ and $k_{2}$ contributions are included in the $400-1400 \mathrm{~cm}^{-1}$ region. 


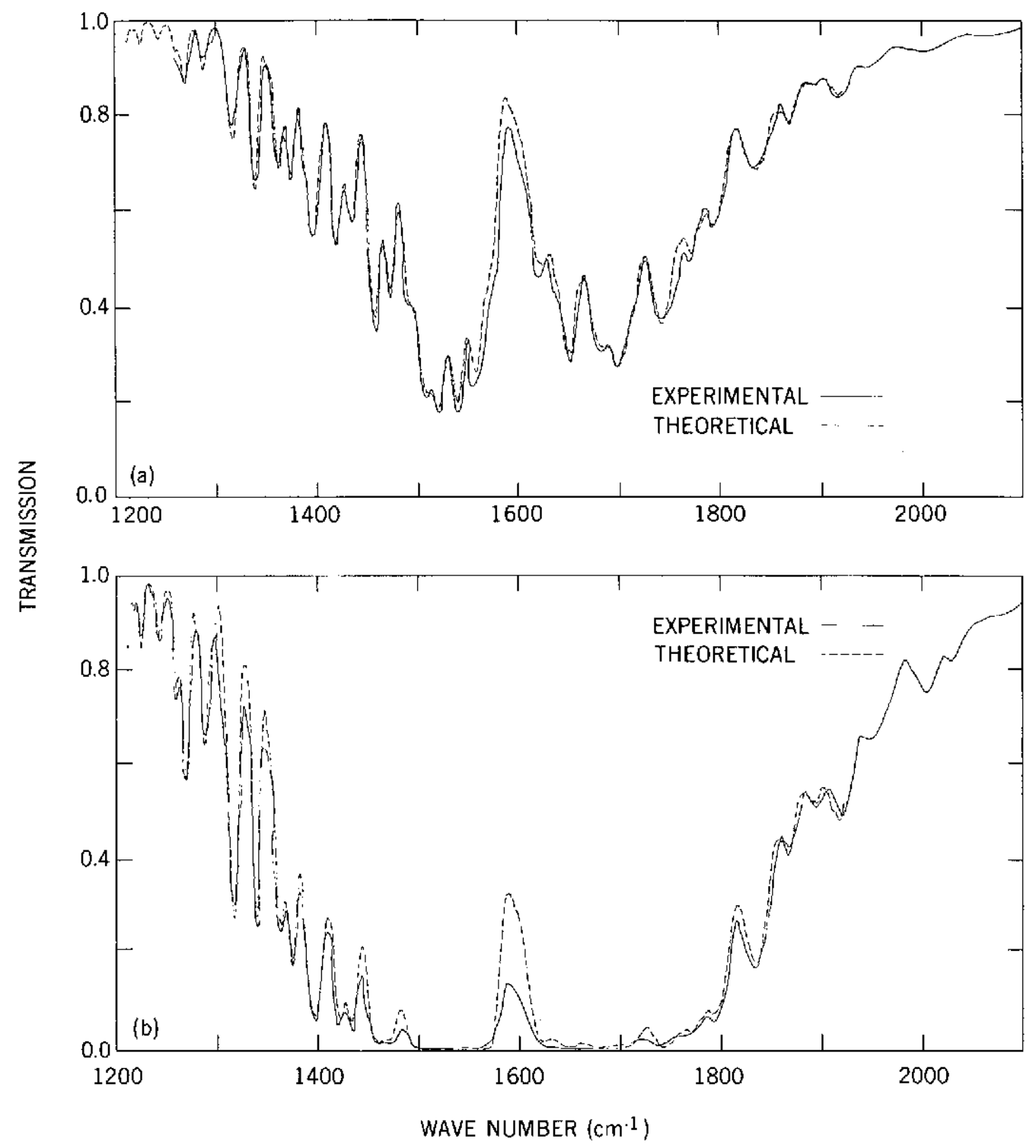

Figure 5. Homogenous path comparison for $1595 \mathrm{~cm}^{-1} \mathrm{H}_{2} \mathrm{O}$ band at room temperature. a) $\mathrm{P}_{\mathrm{e}}=$ $\left.140 \mathrm{mb}, \mathrm{P}=100 \mathrm{mb}, \mathrm{PH}_{2} \mathrm{O}=10 \mathrm{mb}, \mathrm{u}_{2} \mathrm{O}=.0352 \mathrm{pr} \mathrm{cm} ; \mathrm{b}\right) \mathrm{P}_{\mathrm{e}}=1073 \mathrm{mb}, \mathrm{P}=985 \mathrm{mb}, \mathrm{P}_{\mathrm{H}_{2} \mathrm{O}}=$ $22 \mathrm{mb}$, and $\mathrm{u}_{\mathrm{H}_{2} \mathrm{O}}=.077 \mathrm{pr} . \mathrm{cm}$. 


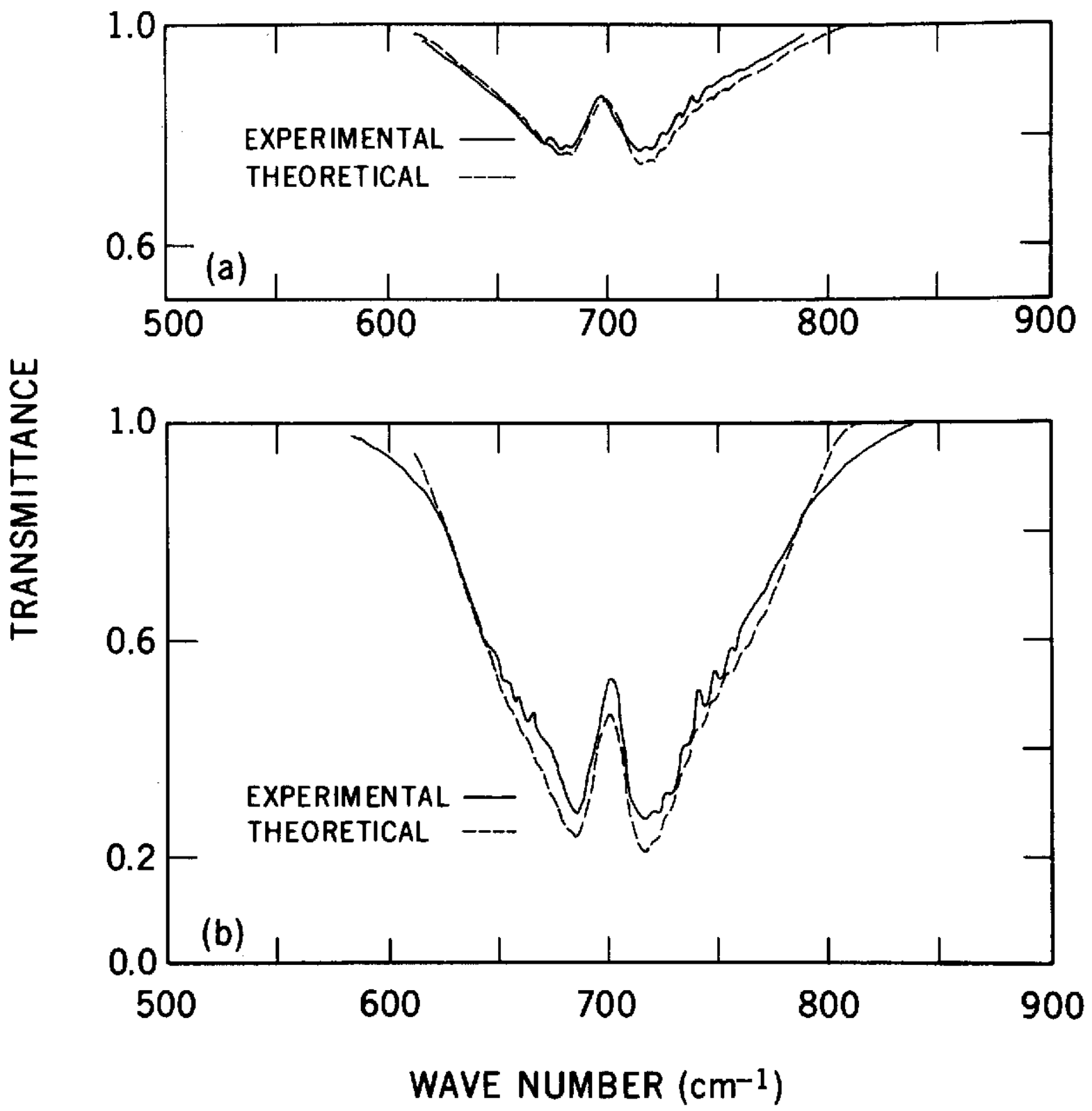

Figure 6. Homogenous path comparison for $701 \mathrm{~cm}^{-1} \mathrm{O}_{3}$ band at room temperature. a) $P=66.6 \mathrm{mb}, \mathrm{u}=2$ crn. atm. b) $P=533 \mathrm{mb}, \mathrm{u}=\mathbf{9 , 4} \mathrm{cm}$. atm. 